\title{
What is the Level of Awareness of Novel Coronavirus (SARS-CoV-2) Among Greek Students in the Days of School Reopening?
}

\begin{abstract}
George Marinos ${ }^{1,11}$, Dimitrios Lamprinos $^{1 *}$, Panagiotis Georgakopoulos ${ }^{1}$, Evangelos Oikonomou $^{2}$, Georgios Zoumpoulis ${ }^{1}$, Christos Damaskos ${ }^{3}$, Nikolaos Garmpis ${ }^{4}$, Anna Garmpi ${ }^{10}$, Athanasios-Dimitrios Bakasis ${ }^{5}$, Eirini Tzalavara1, Gerasimos Siasos ${ }^{2}$, Georgios Rachiotis ${ }^{6}$, Anastasia Swfroni ${ }^{1}$, Anastasia Papaioannou7, Dimitrios Schizas ${ }^{8}$, Alexandros Nikolopoulos ${ }^{9}$ and Georgia Vogiatzi ${ }^{2}$

${ }^{1}$ Emergency Care Department, General Hospital of Athens, Laiko, Greece

${ }^{2} 1$ st Cardiology Clinic, 'Hippokration' General Hospital, National and Kapodistrian University of Athens, School of Medicine, Athens, Greece

${ }^{3}$ Renal Transplantation Unit, Laiko General Hospital, Athens, N.S. Christeas Laboratory of Experimental Surgery and Surgical Research, Medical School, National and Kapodistrian University of Athens, Athens, Greece

${ }^{4}$ Second Department of Propedeutic Surgery, Laiko General Hospital, Medical School, National and Kapodistrian University of Athens, Athens, N.S. Christeas Laboratory of Experimental Surgery and Surgical Research, Medical School, National and Kapodistrian University of Athens, Athens, Greece
\end{abstract}

${ }^{5}$ Pathophysiology Department, National and Kapodistrian University of Athens, School of Medicine, Athens, Greece

${ }^{6}$ Department of Hygiene and Epidemiology, Faculty of Medicine, University of Thessaly, Larissa, Greece

${ }^{7}$ Health Center of Nea Makri, Attica, Greece

${ }^{8}$ First Department of Surgery, National and Kapodistrian University of Athens, Laikon General Hospital, Athens, Greece

${ }^{9}$ Hellenic Swiiming Federation, swimming coach, Greece

${ }^{10}$ First Department of Propedeutic Internal Medicine, Laiko General Hospital, Medical School, National and Kapodistrian University of Athens, Athens, Greece

${ }^{11}$ Affiliation Department of Hygiene, Epidemiology and Medical Statistics Medical School, National and Kapodistrian University of Athens 75, M.Asias Str.Athens 11527, Greece

*Corresponding author: Dimitrios Lamprinos, Emergency Care Department, General Hospital of Athens, Laiko Agiou Thoma 17, PO 11527, General Hospital of Athens, Laiko, Greece

\section{ARTICLE INFO}

Received: 慧 December 06, 2021

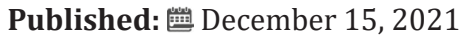

Citation: George Marinos, Dimitrios Lamprinos, Panagiotis Georgakopoulos, Evangelos Oikonomou, Georgios Zoumpoulis, et al., What is the Level of Awareness of Novel Coronavirus (SARS-CoV-2) Among Greek Students in the Days of School Reopening?. Biomed J Sci \& Tech Res 40(4)2021. BJSTR. MS.ID.006473.

\section{ABSTRACT}

Background: Social distancing has been adopted for reducing the outbreak of the evolving pandemic of coronavirus disease 2019 (COVID-19). Among other measures to protect the public, closure of schools has been applied. However, messaging is not always consistent and clear.

Methods: To determine COVID-19 awareness among Greek adolescents, who easily transmit the SARS-CoV-2 during school reopening the self-reported knowledge and behavior have been recorded.

Results: Most of participants were aware about coronavirus and its origin. Nearly one fifth could not correctly identify symptoms (19\%) while only one third agreed about the ways of protection. Interestingly, 85\% have received their information through school and family. Only $18,5 \%$ of the participants knew what quarantine is. Regarding the existence of an effective vaccine, 27,5\% replied positively. In multivariable analysis, male subjects were more aware that COVID-19 has been come to Greece.

Conclusions: The level of information about COVID-19 among Greek students was found to be satisfactory, but not ideal. These findings, along with the potential for a second wave of a COVID-19 pandemic, highlight the need for a more intensive health education program in Greek schools, in order to deal with this serious public health problem. 


\section{Introduction}

Severe acute respiratory syndrome due to coronavirus 2 (SARSCoV-2) and the resultant coronavirus disease 2019 (COVID-19) has raised worldwide health concern since December 2019. As of March $11^{\text {th }}, 2020$, the World Health Organization (WHO) characterized it as a pandemic [1]. Governments all over the world have taken actions to minimize the risk of infection and the spread of the virus [2]. In the context of the social distancing strategies, schools, universities and colleges have closed, in a nationwide or local basis in 190 countries, affecting approximately $73.5 \%$ of the world's student population [3]. Being on the same wavelength, and based on evidence and assumptions from influenza outbreaks that school closures reduce social contacts between students and therefore interrupt transmission, the Greek authorities took the decision to also implement this measure [4]. However, as Greece was highlighted among the countries with the less cases and victims from COVID-19, this measure was taken back and the schools were reopened for the last class of high school in May $4^{\text {th }}$ and one week later for secondary and the rest of the classes of high school. This descriptive study aimed to determine the level of information about the COVID-19 among students of Athens, aged 13 to 18 years. More specifically, we attempted to assess the level of knowledge, as well as their preparedness and ability to react efficiently during the pandemic.

\section{Methods}

\section{Study Design and Sample}

The study was conducted in schools of Athens Area, with a total population of 3,74 million people. The study was approved by the Hospital ethics committee and executed in accordance with the Declaration of Helsinki (1989). Inclusion criteria were voluntary involvement of students living in the Attika area. Common exclusion criteria include the presence of a severe and uncorrectable cognitive, visual, or hearing impairment that would preclude a participant's ability to complete interviews. Participants were not required to record their personal details, nor to answer all questions in the questionnaire. Data were collected from 13 through 20 March 2020. Surveys took less than 10 minutes. In total, 1200 students aged 13 to 18 years were selected, sub-divided in two groups, 13-15 years old and 16-18years old, respectively.

\section{Questionnaire}

Survey items were adapted from questionnaires used to study prior outbreaks [5,6]. The questionnaire consisted of 12 items ( 9 dichotomous questions, and 3 multiple choice) designed to assess students' knowledge of SARS-CoV-2 characteristics, for example: What is COVID-19? How is COVID-19 transmitted? Which are the symptoms and the protection measures? What is the quarantine? Is there a vaccine? Has there ever been a COVID-19 case in Greece?

\section{Statistical Analysis}

Categorical variables were presented as a percentile. Descriptive statistics were calculated for all participant characteristics and survey responses and were presented as valid percentages and as numerical values were appropriate. The chi square test was used to determine statistically significant differences among subgroups of the study's participants. A p value $<0.05$ was considered as statistically significant. SPSS 24 for Windows (SPSS 23 Armonk, NY: IBM Corp) was used for the analysis.

\section{Results}

\section{General Knowledge about SARS-CoV2}

From the total group of 1,200 teenagers aged between 13 and 18 years, $658(54,8 \%)$ were female. Among the participants, $1,044(87 \%)$ knew what the coronavirus is, and 744 (62\%) were aware that the outbreak began from China. When the survey was conducted, the virus had spread to all regions of Italy, while on March $12^{\text {th }}$ the first victim was reported in Greece. Therefore, when participants were asked if the virus had infected people in Europe and Greece, $79,5 \%$ and $74,7 \%$ respectively, answered positively. Interestingly, most of the responders (85\%) were informed by their families or teachers; only 180 of the students (15\%) said that the source of their information about COVID-19 was media and the web.

\section{Symptoms and Transmission of Covid-19}

Study participants were asked about the symptoms of COVID-19; $774(64,5 \%)$ said the symptoms are similar to those of a common cold-like illness, while 198 (16\%) were unaware. Regarding the ways of transmission $54,1 \%$ of them answered through coughing and human contact while 15,9\% of them were not aware. On average one third of responders $(30,5 \%)$ claimed that there is no need for an urgent visit at the hospital if someone is suspected to be infected by the SARS-CoV-2.

\section{Awareness of Ways of Protection}

The study aimed to determine how informed students were about protection measures. Of note, only 66 (5,5\%) and 138 $(11,5 \%)$ recognized the social distancing and avoidance of contacts as effective precaution measures, respectively. More than half of them (53\%) answered that hand washing should be followed. Interestingly, nearly one third agreed that all the above-mentioned measures should be applied by general population to avoid the spread of the disease. Furthermore, only 222 (18,5\%) of the participants knew what quarantine is; 390 (32,5\%) claimed that there is no need for a mask if the person is not infected. Regarding whether an effective vaccine exists, 330 (27,5\%) reported falsely that a vaccine already exists. (Table 1) summarizes respondents' estimations according to their age group. 
Table 1: Knowledge level of participants about COVID-19.

\begin{tabular}{|c|c|c|c|c|}
\hline Questions & \multicolumn{2}{|c|}{$13-15$} & \multicolumn{2}{|c|}{$16-18$} \\
\hline $\operatorname{Sex}(M / F)$ & \multicolumn{2}{|c|}{$274 / 326$} & \multicolumn{2}{|c|}{$268 / 332$} \\
\hline $\begin{array}{l}\text { Have you ever heard about COVID-19 (\%)? } \\
\text { Yes /No }\end{array}$ & $39.8 / 5.8$ & $33.5 / 20.9$ & $39.8 / 4.4$ & $48.2 / 7.6$ \\
\hline $\begin{array}{l}\text { Where the pandemic began }(\%) \text { ? } \\
\qquad \begin{array}{c}\text { China } \\
\text { Italy } \\
\text { USA }\end{array}\end{array}$ & $\begin{array}{c}28.3 \\
14.5 \\
2.9\end{array}$ & $\begin{array}{c}20.6 \\
28.5 \\
5.2\end{array}$ & $\begin{array}{c}26.7 \\
17 \\
1.4\end{array}$ & $\begin{array}{c}35.2 \\
16.1 \\
3.6\end{array}$ \\
\hline $\begin{array}{l}\text { Are there any cases in Europe (\%)? } \\
\text { Yes/No }\end{array}$ & $34.8 / 10.8$ & $33.7 / 20.7$ & $37.5 / 7.1$ & $43.5 / 11.8$ \\
\hline $\begin{array}{c}\text { Are there any cases in Greece (\%)? } \\
\text { Yes/No }\end{array}$ & $33.9 / 11.8$ & $33.7 / 20.6$ & $36.7 / 8$ & $452 . / 10.1$ \\
\hline $\begin{array}{c}\text { Ways of transmission (\%) } \\
\text { Coughing } \\
\text { Human contact } \\
\text { Both } \\
\text { Not aware }\end{array}$ & $\begin{array}{c}5.3 \\
8.5 \\
25.3 \\
6.5\end{array}$ & $\begin{array}{l}12.9 \\
21 \\
9.5 \\
11\end{array}$ & $\begin{array}{l}5.2 \\
5.8 \\
29 \\
4.8\end{array}$ & $\begin{array}{c}8.9 \\
10.1 \\
27.1 \\
9.1\end{array}$ \\
\hline $\begin{array}{l}\text { Symptoms are flu-like (\%)? } \\
\text { Yes } \\
\text { No } \\
\text { I don't know }\end{array}$ & $\begin{array}{c}29.2 \\
8.4 \\
7.8\end{array}$ & $\begin{array}{c}33.8 \\
9.3 \\
11.5\end{array}$ & $\begin{array}{c}31.5 \\
6.5 \\
6.6\end{array}$ & $\begin{array}{c}34.5 \\
11.5 \\
9.4\end{array}$ \\
\hline $\begin{array}{l}\text { Ways of protection (\%) } \\
\text { Social distancing } \\
\text { Avoid contacts } \\
\text { Washing hands } \\
\text { All }\end{array}$ & $\begin{array}{r}2.3 \\
5.4 \\
26.3 \\
11.8\end{array}$ & $\begin{array}{c}5 \\
11.8 \\
27.6 \\
9.8\end{array}$ & $\begin{array}{r}1.8 \\
3.8 \\
23.4 \\
15.7\end{array}$ & $\begin{array}{r}4.1 \\
7.2 \\
27.6 \\
16.4\end{array}$ \\
\hline Is there a vaccine (\%)? Yes/No & $10.2 / 35.5$ & $13.7 / 40.6$ & $16.8 / 32.9$ & $17.1 / 33.3$ \\
\hline $\begin{array}{c}\text { Information through (\%) } \\
\text { Family } \\
\text { School } \\
\text { Media } \\
\text { Internet }\end{array}$ & $\begin{array}{c}18.5 \\
20.1 \\
3.8 \\
3.3\end{array}$ & $\begin{array}{l}33 \\
16 \\
4.8 \\
0.5\end{array}$ & $\begin{array}{c}18.5 \\
19.8 \\
2.6 \\
3.8\end{array}$ & $\begin{array}{c}25.5 \\
23.1 \\
3.5 \\
3.2\end{array}$ \\
\hline Do you know what quarantine is (\%)? Yes/No & $6.9 / 38.8$ & $9.1 / 45.2$ & $10.1 / 34.6$ & $11 / 44.3$ \\
\hline $\begin{array}{l}\text { Wearing masks without having been infected (\%)? Yes/ } \\
\text { No }\end{array}$ & $30.4 / 15.3$ & $30 / 24.3$ & $12.4 / 32.3$ & $21.7 / 33.6$ \\
\hline
\end{tabular}

\section{Data Stratified According to Sex or Age}

After multivariable adjustment, male subjects were more aware that COVID-19 has been come to Greece (78\% vs. $71 \%, \mathrm{p}=0.01$ ). Older students were more aware that COVID-19 has come to Greece compared to younger ones ( $82 \%$ vs. $67 \%, p=0.01$ ), while they were also aware that if they are suspected of having the disease there is no need to go immediately to hospital ( $73 \%$ vs. $66 \%, \mathrm{p}=0.01)$. Nevertheless, the younger compared to older students were more informed that no vaccine exists $(79 \%$ vs. $66 \%, \mathrm{p}<0.001)$ and that the mask should be applied even if the person has not the disease (36\% vs. 29\%, p<0.01) (Figure 1). 

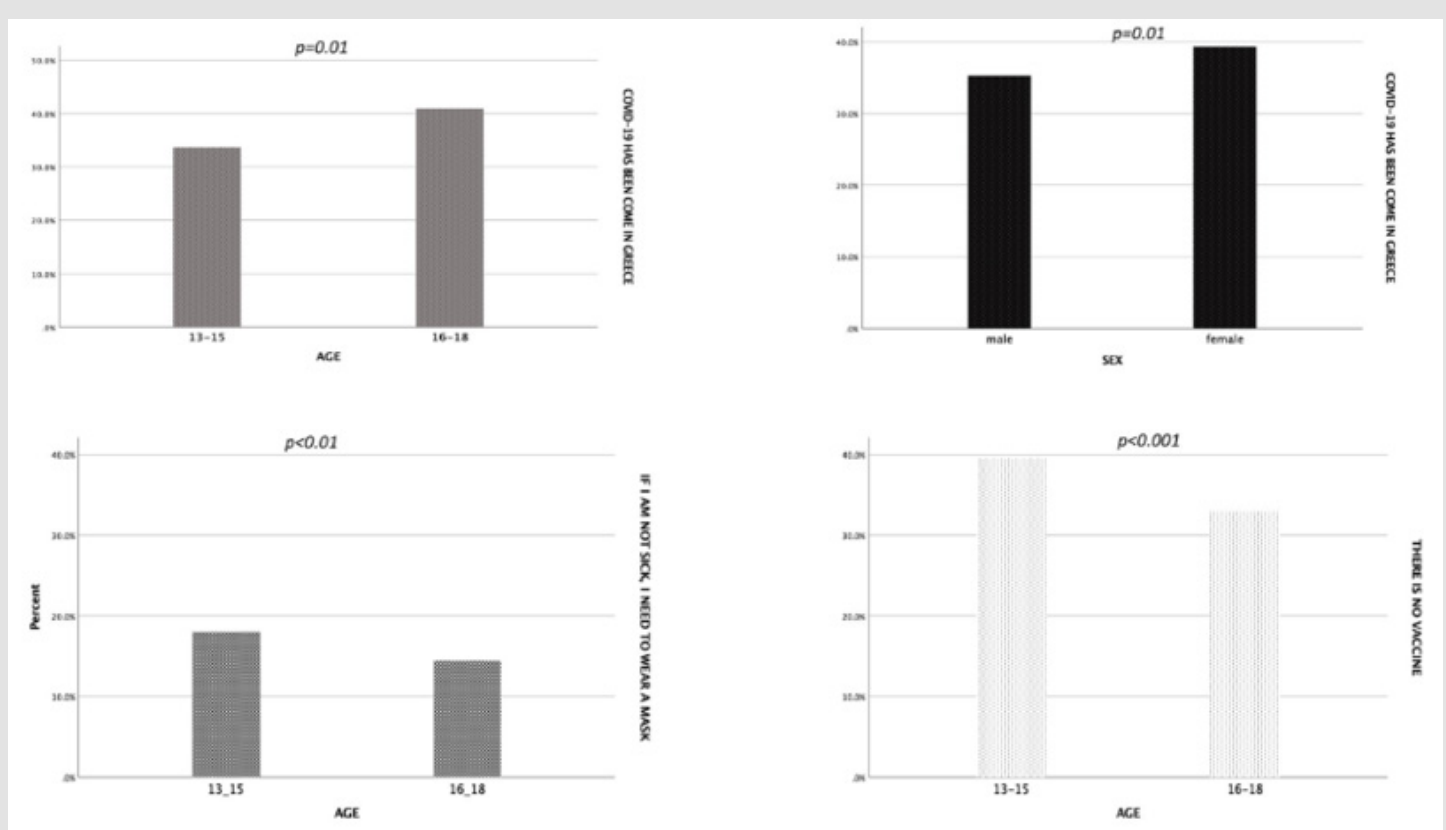

Figure 1.

\section{Discussion}

In a survey of more than 1,200 sociodemographically diverse teenagers, we found that most respondents perceived that they have heard of the coronavirus (COVID-19). However, many are not properly aware about the symptoms and the ways of protection; the one forth could not identify symptoms and almost the one third were totally informed about the proper prevention measures. Another critical point is the use of mask by healthy individuals as two thirds answered that is not necessary. That facts may reflect the blurred image given by the experts regarding the use of the mask. In our study, disparities by sex and age were presented. During the pandemic, Greece managed to react early and effectively. The number of the cases $(2,892)$ and the victims (173) rank Greece in $78^{\text {th }}$ position [7]; international mass media praise Greece's handling of outbreak as a surprising success story. As a consequence, from the beginning of May, most activities gradually return to normal, employees go back to work, various public restrictions ceased, bar and restaurant reopened. Whilst pandemic globally exists, Greek government outweighing the benefits for children's education and mental health, decided to reopen schools in $7^{\text {th }}$ September. Several studies of COVID-19 hint that children are less likely to catch the novel coronavirus, and they don't often transmit it to others $[8,9]$. Relying on those encouraging data and the reassuring knowledge that very few children get severely ill from COVID-19 other governments, amongst then Denmark, Germany and Israel have already reopened schools.
The measures are tentative as most schools are resuming with reduced class sizes, shortened school days, and extra handwashing, while spots, which outbid about social distancing are flooding the media. However, some scientists worry about the risks, as even if the possibilities of transmission are low, the web of contacts makes the tracking process difficult. Our study, working to quickly capture the opportunity to investigate the level of awareness in teenagers, has clear limitations. First, the survey was conducted among a selected group of students only in the Attika region. Therefore, there is no knowledge how semi-urban and rural areas are informed regarding coronavirus. However, our study samples purposefully include girls and boys from schools socioeconomically diverse. Prior research on virus outbreaks guided our selection and creation of survey items $[5,6]$. However, items followed best practices for the design of assessments for use among persons with lower literacy [10]. Third, our outcomes capture only initial awareness of COVID-19, fundamental knowledge, attitudes, and a limited set of behaviors. However, understanding of the virus has since quiete evolved, and we could not expand on those developments. Items included in planned follow-up waves of the survey will adapt accordingly.

Finally, public health messages about new policies and restrictions dramatically change day to day. Regardless, our findings depict the initial lack of clarity in understanding and perceived susceptibility, among teenagers regarding pandemic. Bearing in mind our findings, actions and cooperation are needed amongst local authorities, health boards, trade unions, public health, disease 
control experts, and schools, to ensure that as long as the pandemic exists, all teenagers are adequately made aware of the gravity of the threat.

\section{Conclusion}

The level of information about COVID-19 among Greek students aged 13 to 18 years was found to be not ideal but adequate. Although the students were found informed on some aspects, they were unfamiliar with other important issues. In the light of a potential second wave of COVID-19 pandemic, our findings highlight the need for intensified health education programs in Greek schools in order to deal with this serious emerging health problem.

\section{Conflict of Interest}

None.

\section{Acknowledgment}

None.

\section{Funding}

None.

\section{References}

1. (2020) WHO. WHO Director-General's opening remarks at the Mission briefing on COVID-19.

\section{ISSN: 2574-1241}

DOI: $10.26717 /$ BJSTR.2021.40.006473

Dimitrios Lamprinos. Biomed J Sci \& Tech Res

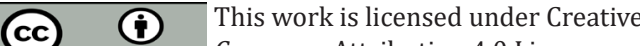

Submission Link: https://biomedres.us/submit-manuscript.php
2. (2020) Worldometer. COVID-19 coronavirus outbreak.

3. (2020) UNESCO. COVID-19 Educational Disruption and Response. UNESCO.

4. Jackson C, Vynnycky E, Mangtani P (2016) The Relationship Between School Holidays and Transmission of Influenza in England and Wales. American journal of epidemiology 184(9): 644-651.

5. Marinos G, Vasileiou I, Katsargyris A, Klonaris C, Georgiou C, et al. (2007) Assessing the level of awareness of avian influenza among Greek students. Rural and remote health 7(3): 739.

6. Kelly B, Squiers L, Bann C, Stine A, Hansen H, et al. (2015) Perceptions and plans for prevention of Ebola: Results from a national survey. BMC public health 15: 1136

7. 2020 .

8. Wise J (2020) Covid-19: Delaying school reopening by two weeks would halve risks to children, says iSAGE. BMJ 369: m2079.

9. Ioannidis JPA (2020) Coronavirus disease 2019: The harms of exaggerated information and non-evidence-based measures. European journal of clinical investigation 50(4): e13223.

10. Shoemaker SJ, Wolf MS, Brach C (2014) Development of the Patient Education Materials Assessment Tool (PEMAT): A new measure of understandability and action ability for print and audiovisual patient information. Patient education and counseling 96(3): 395-403.

$\begin{array}{ll}\text { BIOMEDICAL } & \text { Assets of Publishing with us } \\ \text { RESEARCHES } & \text { - Global archiving of articles } \\ & \text { - Immediate, unrestricted online access } \\ & \text { - Rigorous Peer Review Process } \\ & \text { - Authors Retain Copyrights } \\ \end{array}$

